\title{
Miniaturized multiparametric flexible platform for the simultaneous monitoring of ionic: Application in real urine
}

\author{
Ana Moya ${ }^{\mathrm{a}, \mathrm{d}, \mathrm{e}}$, Xavi Illa $^{\mathrm{a}, \mathrm{d}}$, Ignacio Gimenez ${ }^{\mathrm{b}}$, Yoskaly Lazo-Fernandez ${ }^{\mathrm{b}}$, Rosa Villa ${ }^{\mathrm{a}, \mathrm{d}}$, \\ Abdelhamid Errachid $^{\mathrm{c}}$, Gemma Gabriel ${ }^{\mathrm{a}, \mathrm{d}, *}$ \\ a Instituto de Microelectrónica de Barcelona, IMB-CNM (CSIC), Esfera UAB, Campus Universitat Autònoma de Barcelona, 08193 Bellaterra, Barcelona, Spain \\ b Instituto Aragonés de Ciencias de la Salud (IACS), IIS Aragón, Universidad de Zaragoza, Spain \\ ' Université de Lyon, Institut des Sciences Analytiques, UMR 5280, CNRS, Université Lyon 1, ENS Lyon, 5 rue de la Doua, F-69100 Villeurbanne, France \\ d Biomedical Research Networking Center in Bioengineering, Biomaterials and Nanomedicine (CIBER-BBN), Spain \\ e PhD in Electrical and Telecommunication Engineering, Universitat Autoǹoma de Barcelona (UAB), Spain
}

\section{A R T I C L E I N F O}

\section{Article history:}

Received 9 June 2017

Received in revised form 31 August 2017

Accepted 15 September 2017

Available online xxx

\section{Keywords:}

Multi-Sensor

Miniaturization

Microelectrodes

Polyimide

DO sensor

$\mathrm{Na}^{+} / \mathrm{K}^{+} \mu \mathrm{ISE}$

$\mathrm{pH}$ sensor

\begin{abstract}
A B S T R A C T
Biomonitoring is a research topic that has largely relied on cell culture systems. Recently, the development of "Organ-on-a-Chip" (OC) platforms and the need for a continuous monitoring of these systems has increased its interest. However, the biomonitorization in these systems is still at its infancy due to the difficulty to adapt the sensors to microfluidic OC systems. In this work we have fabricated a modular, versatile, scalable, multi-analyte sensing platform, which integrates dissolved oxygen (DO), $\mathrm{Na}^{+}, \mathrm{K}^{+}$and $\mathrm{pH}$ sensors for monitoring their concentrations in small volume of biological fluids. The platform is fabricated by means of rapid prototyping techniques using polymeric substrates, and incorporates all the necessary elements to measure the four analytes. It was designed with four gold sensing electrodes, and integrates a gold counter electrode and an $\mathrm{Ag} / \mathrm{AgCl}$ pseudo-reference electrode for the electrochemical measurements in small volumes $(0.83 \mu \mathrm{L})$ of samples. The sensors featured good sensitivities of $3.60 \pm 0.2 \mathrm{nA}\left(\mathrm{mg} \mathrm{L}^{-1}\right)$ for $\mathrm{DO}$ and $69 \pm 1 \mathrm{mV}$ decade ${ }^{-1}$ for $\mathrm{pH}$. $\mathrm{Na}^{+}$and $\mathrm{K}^{+} \mu$ ISE exhibited sensitivities of $57 \pm 1 \mathrm{mV}$ decade $^{-1}$ and $52 \pm 2 \mathrm{mV}$ decade $^{-1}$, and low limits of detection $5 \times 10^{-6} \mathrm{M}$ and $0.5 \times 10^{-5} \mathrm{M}$ respectively. This platform allows the dynamic measurement of the biological fluids parameters simultaneously, in real time and with a rapid response. The versatility of the platform allows its adaptation in any microfluidic cells culture systems. The novel multi-sensor platform has been validated in controlled buffers and with artificial urine (AU). A proof-of-concept using real mice urine (RU) has been carried out, demonstrating the good behaviour of the multi-sensing platform.
\end{abstract}

(c) 2017 Elsevier B.V. All rights reserved.
Abbreviations: o-NPOE, 2-nitrophenyl octyl ether; AEIROF, anodically electrodeposited iridium oxide films; $\mathrm{AU}$, artificial urine; $\mathrm{CE}$, counter electrode; CV, cyclic voltammetry; COP, cyclo-olefin polymer; DBP, dibutyl phosphate; DOS, dioctyl sebacate; DO, dissolved oxygen; PPy, electropolymerized pyrrole; IrOx, iridium oxide; LOD, limit of detection; LOQ, limit of quantification; PBS, phosphatebuffered saline; OOC, Organ-on-a-Chip; PET, Polyethylene terephthalate; PMMA, Polymethymethacrylate; PET, Polyethylene terephthalate; PVB, polyvinyl butyral; PVC, polyvinylchloride; pRE, pseudo reference electrode; RU, real urine; SEM, Scanning Electron Microscope; THF, tetrahydrofuran; 2D, two-dimensional; WE, working electrode; ZIF, zero insertion force; MPM, matched potential method; $\mu$ ISE, micro ion-selective electrodes.

* Corresponding author at: Instituto de Microelectrónica de Barcelona, IMB-CNM (CSIC), Esfera UAB, Campus Universitat Autònoma de Barcelona, 08193 Bellaterra, Barcelona, Spain.

\section{Introduction}

The growth of a cell culture is a complex biological process that requires monitoring of various biological parameters in real time. Conventional two-dimensional (2D) cell culture systems are being largely used, but often the results obtained from these systems do not readily translate to in-vivo scenarios due to the fundamental difference of these reductive models compared with native tissues and organs [1]. It is in this context where microfluidic cell culture systems [2-5] and more advanced "Organ-on-a-Chip" systems (OC) have emerged to recreate a more physiological microenvironment [6-10].

In the field of biomonitoring, the interest in integrating sensors for in situ monitoring of cell growth has increased in the last decade [11-13]. Up to now, most of the systems which present miniaturized devices with integrated electrochemical sensors are 
still based on static cell cultures systems $[14,15]$. However, multiparameter electrolyte monitoring in microfluidic cell cultures is barely used and poses challenges. Conventional analytical methods require manual sample collection from the microfluidic system, large working volumes, and frequent system disturbance, and thus are not suitable for miniaturized platforms.

The analysis of real samples implies the determination of several ions. Analytes of interest are related to acidification, respiration and some ions, such as sodium and potassium among the most general ones [16,17]. Oxygen consumption [18] and acidification [19] are both indicative of cell metabolism. They are among the most relevant biological parameters, well suited for the sensitive detection of cellular response to drugs or toxic compounds or just to monitor of cell life activity [20]. Monitoring of extracellular ion activities can be of interest in applications involving the study of tissue/organs whose function is sensitive to extracellular ion concentrations (excitable cells like neurons or muscle) or depends on the establishment and maintenance of ion concentrations gradients through epithelial barriers [11].

In order to obtain biologically relevant information, it is necessary to use a system capable to measure multiple ions from small volumes in a greatly short and real time. To achieve this, the miniaturization and the simultaneous measurement of ions are important issues for the application; however, it is also necessary to achieve a cost-effective system. The use of polymeric substrates for developing microfluidic systems for electrochemical applications has increased during the last years [21-23]. Specifically, several studies have presented platforms for potentiometric measurements made with flexible polyimide Kapton ${ }^{\circledR}[24,25]$ overcoming the cost limitations that suppose the use of silicon substrates. The use of Kapton ${ }^{\circledR}$ as a substrate has many attractive properties in contrast to other low-cost materials such as thermal and mechanical stability, high chemical resistance, and low dielectric constants.

In this contribution we present a single low-cost platform based on Kapton ${ }^{\circledR}$ and encapsulated on a microfluidic device using laminated polymers by means of rapid prototyping techniques [26,27]. It incorporates four electrochemical sensors for the non-invasive measurement of: dissolved oxygen (DO), $\mathrm{Na}^{+}, \mathrm{K}^{+}$and $\mathrm{pH}$. The electrode array is formed by 4 gold electrodes, one working electrode (WE) for the amperometric measurement, and three other electrodes for each potentiometric measurement, a common integrated $\mathrm{Ag} / \mathrm{AgCl}$ pseudo reference electrode ( $\mathrm{pRE}$ ), and a gold counter electrode (CE). For $\mathrm{Na}^{+}$and $\mathrm{K}^{+}$measurements, microsensors are based in the most common construction of micro ion-selective electrodes ( $\mu$ ISE) which consist on an ion-selective polymeric membrane containing the specific ionophore $[28,29]$. The polymeric membrane is deposited on top of a conducting polymer material based on electropolymerized pyrrole (PPy) layer since is one of the most stable contact layer known [30,31]. The $\mathrm{pH}$ sensor is obtained with the electrochemical coating iridium oxide (IrOx) layer of its sensing electrode [32,33].

Special care has been taken with the combination and integration of all the different sensors, because the fabrication methods need to be compatible. Another goal was to find conditions for sensor storage preserving adequate sensitivity and selectivity for the detection of several analytes.

As a proof of concept, the platform was validated measuring the $\mathrm{Na}^{+}, \mathrm{K}^{+}$ions and $\mathrm{pH}$ using artificial urine samples (AU) with different ion concentration levels and also with real mouse urine (RU) samples obtained from mice fed with gel food formulated to contain varying amounts of sodium and potassium. DO in urine is not a relevant physiological parameter and has to be measured under very stringent conditions that cannot be met with the use of stored samples. However, oxygen control is essential for cell cultures systems since is vital in the energy metabolism of cells and, moreover it is an important regulatory parameter, influencing cell differentiation and tissue zonation [34,35]. We are currently using this platform for DO measurements successfully, in projects involving monitoring of metabolic activity in human cell cultures.

Our efforts have been focused on developing a more realistic device that combines low volume microfluidics with multi-analyte sensing, allowing the detection in biological fluids (including cell culture media) of different ions simultaneously. Special attention has been done in fabricating a versatile, modular, scalable platform that can be placed in series with different microfluidic cell culture systems, to monitor chemical species in real time. Simplicity in the design and miniaturization of multisensing platform will facilitate adapting the platform to sense other analytes in cell culture monitoring.

\section{Material and methods}

\subsection{Reagents}

All solutions used in the sensors development were prepared with deionized water (conductivity less than $1 \mu \mathrm{cm}^{-1}$ ). Although specified, all the reagents were bought at Sigma-Aldrich, and used as received. For the electrode surface cleaning, activation and characterization were used ethanol (LC/MS grade), sodium nitrate $\left(\mathrm{KNO}_{3}\right)$, potassium hexacyanoferrate(III) $\mathrm{K}_{3}\left[\mathrm{Fe}(\mathrm{CN})_{6}\right]$ and potassium hexacyanoferrate(II) $\mathrm{K}_{4}\left[\mathrm{Fe}(\mathrm{CN})_{6}\right]$. For the integration of the pRE were used a commercial silver solution (silvrex-s) from Enthone-Omi; ammonia, nitric acid $\left(\mathrm{HNO}_{3}\right)$, hydrochloric acid $(\mathrm{HCl})$, polyvinyl butyral (PVB), methanol and sodium chloride $(\mathrm{NaCl})$. For the development of the $\mathrm{pH}$ sensor were used iridium trichloride trihydrate $\left(\mathrm{IrCl}_{3} \cdot 3 \mathrm{H}_{2} \mathrm{O}\right)$, oxalic acid $\left(\mathrm{H}_{2} \mathrm{C}_{2} \mathrm{O}_{4} \cdot 2 \mathrm{H}_{2} \mathrm{O}\right)$ and potassium carbonate $\left(\mathrm{K}_{2} \mathrm{CO}_{3}\right)$. For pH sensor calibration was used $\mathrm{HCl}$ and sodium hydroxide $(\mathrm{NaOH})$. For the preparation of the $\mu$ ISE were used 2-nitrophenyl octyl ether (o-NPOE), dioctyl sebacate (DOS), dibutyl phosphate (DBP), potassium tetrakis(4-chlorophenyl)borate (KTpClPB), polyvinylchloride (PVC), potassium ionophore I, sodium ionophore X, tetrahydrofuran (THF), chloroform, acetonitrile, pyrrole, $\mathrm{NaCl}$ and cobaltabis (discarbollide) ions $\left(\mathrm{Cs}\left[\mathrm{Co}\left(\mathrm{C}_{2} \mathrm{~B}_{9} \mathrm{H}_{11}\right)_{2}\right]\right.$ from KATCHEM spol. The nitrate salts of all cations used for the characterization $\left(\mathrm{Na}^{+}, \mathrm{K}^{+}\right.$, $\left.\mathrm{Li}^{+}, \mathrm{Ca}^{2+}, \mathrm{Mg}^{2+}\right)$ were of the highest purity available. Phosphatebuffered saline (PBS) was used to storage the sensors. Finally, for the preparation of $\mathrm{AU}$ samples were used urea, uric acid, creatinine, $\mathrm{Na}_{3} \mathrm{C}_{6} \mathrm{H}_{5} \mathrm{O}_{7} \cdot 2 \mathrm{H}_{2} \mathrm{O}, \mathrm{NaCl}, \mathrm{KCl}, \mathrm{NH}_{4} \mathrm{Cl}, \mathrm{CaCl}_{2} \cdot 2 \mathrm{H}_{2} \mathrm{O}, \mathrm{MgSO}_{4} \cdot 7 \mathrm{H}_{2} \mathrm{O}$, $\mathrm{NaHCO}_{3}, \mathrm{NaC}_{2} \mathrm{O}_{4}, \mathrm{Na}_{2} \mathrm{SO}_{4}, \mathrm{NaH}_{2} \mathrm{PO}_{4} \cdot \mathrm{H}_{2} \mathrm{O}$ and $\mathrm{Na}_{2} \mathrm{HPO}_{4}$.

\subsection{Equipment}

All measurements were carried out at room temperature. The activation and characterization of the gold electrodes, and also the electrodeposition of the IrOx and PPy films, were performed in a single compartment cell with a standard three-electrode system using an 8-channel potentiostat (1030A Electrochemical Analyzer, from $\mathrm{CH}$-Instruments). These experiments were done using a commercial $\mathrm{Ag} / \mathrm{AgCl}$ double junction reference electrode (from Thermo Orion), and a platinum ring electrode as auxiliary electrode (from Metrohm). The silver of the pRE was electrodeposited vs a platinum film, by an Autolab (PGSTAT 12, from Chemie BV). Scanning Electron Microscopy (SEM, Auriga-40, from Carl Zeiss) was used to study the morphology of the electrodeposited films.

The oxygen sensor was calibrated in controlled dissolved solutions against an oxygen probe (OXI 325, from WTW). Oxygen concentrations were changed by a nitrogen-air distributor. DO sensor calibration and the characterization [35] was done using the 8-channel potentiostat (1030A Electrochemical Analyzer, from $\mathrm{CH}$ Instruments). The $\mathrm{pH}$ sensor calibration was done in different $\mathrm{pH}$ 


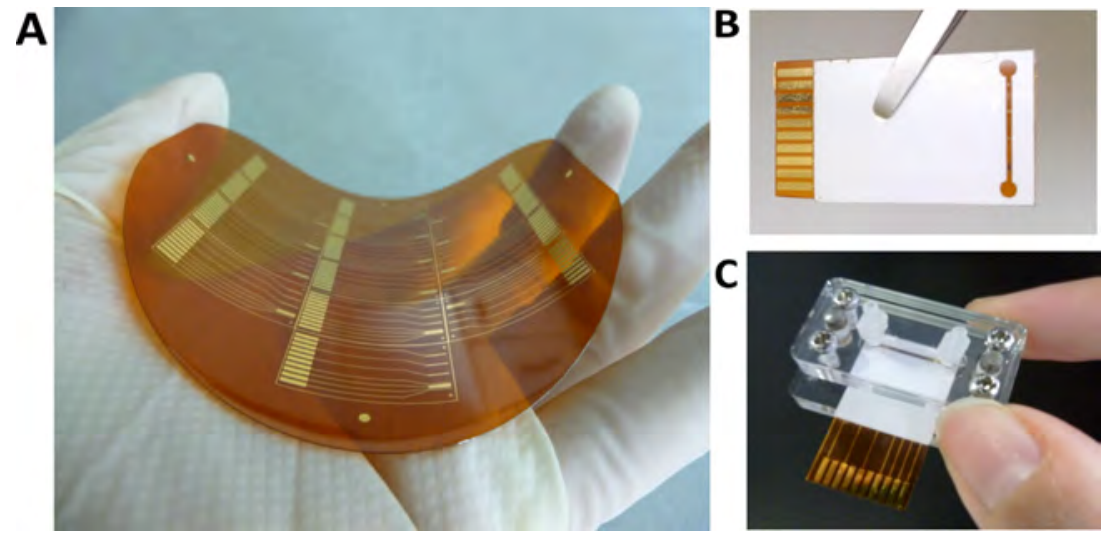

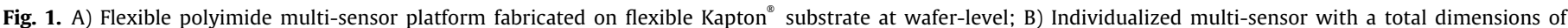
$14 \times 25 \mathrm{~mm}$, passivated by PET sheet which defines the microfluidic channel of $9.5 \times 0.5 \mathrm{~mm}$; C) PMMA custom holder for fluidic and electrical access.

solutions and a commercial $\mathrm{pH}$-meter was used for the correlation of the obtained potentials (GLP22, from Crison). The calibration of the $\mathrm{pH}$ and $\mu$ ISE sensors were done using home-made data acquisition system set-up with four multi-channel microelectrodes to measure open circuit potential, connected and controlled by a personal computer. For all calibrations was used a magnetic stirrer to quickly homogenize their concentrations.

For the experimental validation, the measured $\mathrm{Na}^{+}, \mathrm{K}^{+}$ions of different sample of mouse urine were correlated using an atomic spectrometer (929 Solar AA Spectrometer, ATI Unicam, from Prince Technologies B.V).

\subsection{Microfluidic platform fabrication}

The multi-sensor platform is composed of three different polymeric layers. The bottom one is a $127 \mu \mathrm{m}$ thick polyimide film (Kapton ${ }^{\circledR} 500 \mathrm{HN}$, DuPont) that incorporates an array of six gold microelectrodes: four gold electrodes, a WE for the amperometric measurement, and three for each potentiometric measurement, a pRE and a CE. The middle layer is a structured Polyethylene terephthalate (PET)-two-side adhesive sheet of $175 \mu \mathrm{m}$ of thickness (AR8939, obtained from Adhesives Research Europe) where the microfluidic channel is defined, and the top layer is a $188 \mu \mathrm{m}$ cyclo-olefin polymer (COP) film (Zeonex ZF14-188, purchased from Ibidi $\mathrm{GmbH}$ ) that acts as a cover and where the inlet and outlet of the microfluidic channel are defined.

The platform was fabricated in the clean room facilities of the IMB-CNM (CSIC), at a wafer level (Fig. 1A). In brief, 10/100 nm Ti/Au layers were evaporated on the Kapton ${ }^{\circledR}$ film to fabricate the microelectrodes via lift-off using the AZ5214E image reversal photoresist. The Ti layer was used to improve the adhesion between gold electrodes and polymeric substrate. The active area of the electrodes and the geometry of the microfluidic channel were defined by structuring a PET-two-side adhesive sheet and bonding it to the Kapton ${ }^{\circledR}$ substrate, obtaining a total channel dimension of $9.5 \mathrm{~mm} \times 0.5 \mathrm{~mm}$. The sample volume required to fill the channel is $0.83 \mu \mathrm{L}$. This passivation strategy avoids further passivation and reduces fabrication time and costs. A COP sheet was used to close the channel due its optical transparency as it is necessary to observe inside the channel. Both, COP and PET sheets were cut in Roland GX-24 cutter plotter and were manually aligned using a custom made tool [27]. After the fabrication and encapsulation processes, the sensors were individualized by cutting them using the cutter plot obtaining 14 sensors per wafer with total dimensions of $14 \mathrm{~mm}$ x $25 \mathrm{~mm}$ (Fig. 1B). The connection to the electrode pads was done by using a zero insertion force (ZIF) connector. This strategy reduces the costs and the fabrication time and also allows the reusability of the connectors.
Finally, a custom holder fabricated in polymethymethacrylate (PMMA) was used for easy handling of the chip as shown in Fig. 1C. The holder was designed in order to have both fluidic and electrical access to the electrodes in a reliable and simple manner and with the possibility to place and remove the chip in an easy way.

\subsection{Sensors development}

Microelectrodes require activation before its use. Among the different gold-cleaning methods investigated [36], we chose the application of a suitable potential waveform to clean the multisensor platform. In particular, five pulses alternating between $2 \mathrm{~V}$ and $0 \mathrm{~V}$ during $10 \mathrm{~s}$ in a $\mathrm{KNO}_{3}$ electrolyte solution were performed. Adequate electrode activation was indicated by Ip and $\Delta \mathrm{Ep}$ values consistent reversible electrode kinetics [37]. For this, cyclic voltammetry (CV) measurements in ferro/ferricyanide $\left(10^{-2} \mathrm{M}\right)$ were carried out in static and dynamic way. Before activation, the electrodes were cleaned by sonication in ethanol for $5 \mathrm{~min}$ and rinsed in deionized water to remove grease and organic deposits.

\subsection{1. $p R E$ development}

The integrated pRE was developed by electrodepositing silver onto the gold microelectrode (electrode labelled 1 in Fig. 2A). The active area of the pRE was $0.05 \mathrm{~mm}^{2}$. The sensor surface was submerged in the silver solution, with a concentration of $32 \mathrm{~g} / \mathrm{L}$, and a constant current of $10 \mu \mathrm{A}$ during $120 \mathrm{~s}$ was applied. After that, in order to achieve the purity of the silver layer, the surface was cleaned submerging it in concentrated ammonia during $1 \mathrm{~h}$ and after, in $\mathrm{HNO}_{3}(0.1 \mathrm{M})$ during $2 \mathrm{~h}$ [38]. For the chlorination, the electrodes with the silver film were submerged in $\mathrm{HCl}(0.1 \mathrm{M})$ and a voltammogram from $0 \mathrm{~V}$ to $0.2 \mathrm{~V}$ was applied. In order to achieve a stable $\mathrm{Ag} / \mathrm{AgCl} \mathrm{pRE}$ in presence of different ion compounds, a PVB solution in methanol where $\mathrm{NaCl}$ was dispersed, was drop-casted onto the pRE. This type of membrane presents an outstanding stability to change in solution concentration, light, $\mathrm{pH}$ and redox potential [39]. Stability of the pRE potential was studied for $24 \mathrm{~h}$ in a $\mathrm{KCl}(3 \mathrm{M})$ solution exhibiting a good stability with a drift rate less than $0.11 \mathrm{mVh}^{-1}$. Fig. 2A.1 shows the SEM image of a $\mathrm{Ag} / \mathrm{AgCl}$ pRE integrated in the platform before the deposition of the PVB membrane.

\subsubsection{DO sensor development}

DO was measured with amperometric method. Clark type microsensors [40] are the most commonly used probes in this type of measurement, where a polarized potential is applied to the WE and the reduction of the current generated at it is directly proportional to the oxygen concentration of the solution. The necessary 

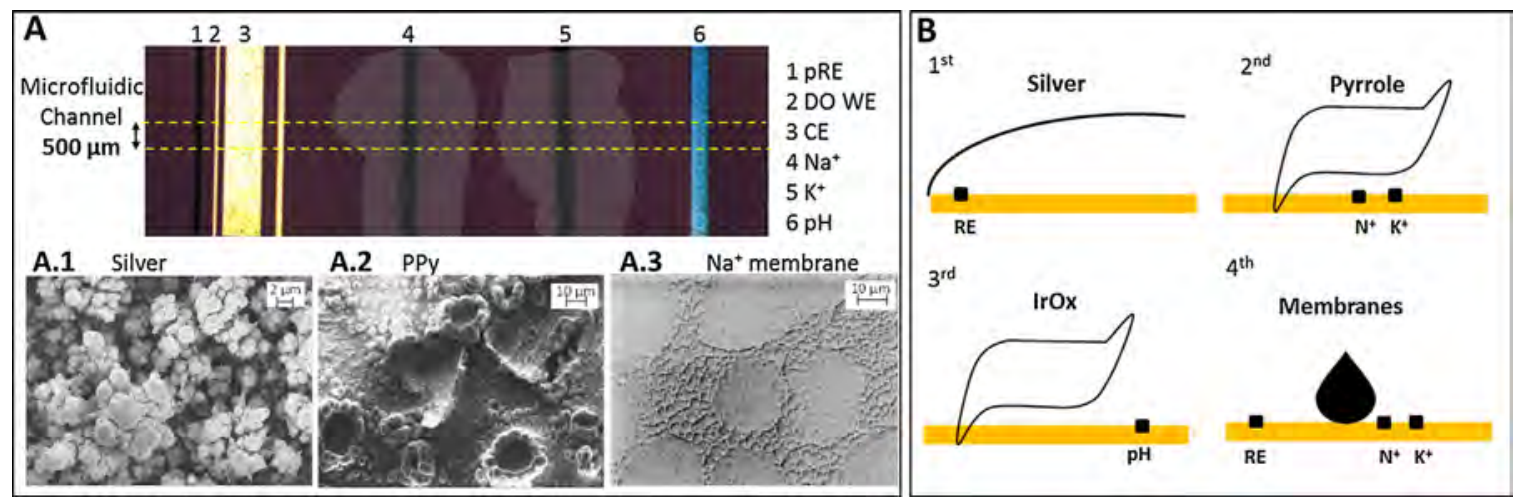

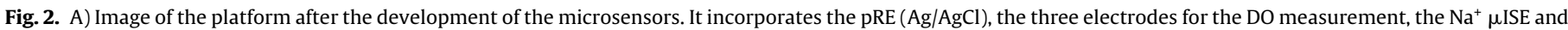

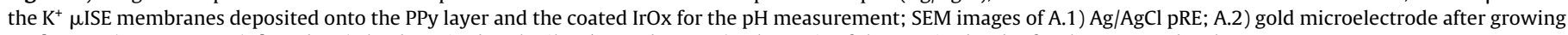
$\operatorname{PPy}\left[3,3^{\prime}-\mathrm{Co}(1,2-\mathrm{C} 2 \mathrm{~B} 9 \mathrm{H} 11) 2\right]$; and A.3) the deposited cocktail $\mathrm{Na}^{+}$membrane, B) Schematic of the required order for the sensors development processes.

three electrodes were integrated in our platform; a pRE (electrode labeled 1 in Fig. 2A), a WE (electrode labelled 2 in Fig. 2A) and a CE (electrode labelled 3 in Fig. 2A). The active area of the CE was $0.25 \mathrm{~mm}^{2}$, ten times higher than area of the WE $\left(0.025 \mathrm{~mm}^{2}\right)$. Sensors were calibrated in the oxygen concentration range between 0 and $8 \mathrm{mg} \mathrm{L}^{-1}$ DO as it is well described in our previous work [35]. The sensor was polarized at $-850 \mathrm{mV}$ as the optimal potential value for the determination of the DO concentration. The DO concentration was adjusted by bubbling different nitrogen $\left(\mathrm{O}_{2}\right.$ free $)$ - air $\left(21 \% \mathrm{O}_{2}\right)$ mixtures through a $\mathrm{KNO}_{3}(0.1 \mathrm{M})$ solution, and a magnetic stirrer was used to ensure better mixing of the solution. The concentration of DO in the cell was measured with a commercial DO probe and correlated with the measured polarization currents of each microelectrode in order to build the calibration curves. Sensor resolution was evaluated using a definition of limit of quantification (LOQ) and limit of detection (LOD) defined by IUPAC [41]. LOQ is equal to the blank conditions $\left(0 \% \mathrm{O}_{2}\right)$ plus ten times their standard deviation. The LOD is obtained with the same blank conditions plus three time their standard deviation.

\subsection{3. $\mathrm{Na}^{+}$and $\mathrm{K}^{+}$sensor development}

$\mathrm{Na}^{+}$and $\mathrm{K}^{+}$were measured with a potentiometric method. The most common construction of the $\mu$ ISE requires an ion-selective membrane of a polymeric type containing the specific ionophore [28]. PVC is conventionally used as a membrane matrix since PVCmembrane enhances the retention of the membrane components and extends the lifetime of the electrode [29]. In addition, a conventional ISE has an inner electrolyte solution that makes more difficult its miniaturization. In order to solve it, many investigations have been dedicated to the replacement of the internal solution for a conducting polymer used as a solid-contact layer [42,43].

In this work, for the development of the $\mu$ ISE, a conductive solid internal contact layer between the gold electrode and the sensing membrane was prepared by electropolymerization of the pyrrole $\left(10^{-1} \mathrm{M}\right)$ in presence of $\mathrm{Cs}\left[\mathrm{Co}\left(\mathrm{C}_{2} \mathrm{~B}_{9} \mathrm{H}_{11}\right)_{2}\right]\left(3.5 \times 10^{-2} \mathrm{M}\right)$ in acetonitrile over the surface of the gold sensing electrode (electrode labelled 4 and 5 in Fig. 2A), with an area of $0.1 \mathrm{~mm}^{2}$. The high over oxidation resistance provided by the cobaltabis(discarbollide) represents a significant improvement in the long term stability of such membranes as it is described in [44]. The electrodeposition conditions of the PPy films were carefully studied to ensure the best adhesion and charge transfer between the electrodes and the membranes. The best response was obtained by applying a redox potential from $-0.2 \mathrm{~V}$ to $1.1 \mathrm{~V}$ at a scan rate of $100 \mathrm{mV} \mathrm{s}^{-1}$ during 10 cycles. Fig. 2A.2 shows a SEM image of the electrodeposited PPy layer.
Finally, different PVC-membranes compositions were studied. In particular, three different membranes with different plasticizers were prepared and studied, since the solvent used in the composition of the membranes influences the characteristics of microelectrodes, such as the dielectric constant of the membrane and the mobility of the ionophore molecules [45]. They were prepared by mixing $1 \mathrm{wt} . \%$ of commercial ionophore, $33 \mathrm{wt} . \%$ of PVC matrix, $65.5 \mathrm{wt} . \%$ of plasticizer (DOS, o_NPOE or DBP) and $0.5 \mathrm{wt} . \%$ of KTpClPB additive; all dissolved in $5 \mathrm{~mL}$ of THF with $0.5 \mathrm{~mL}$ of chloroform [46-48]. This mixture was deposited manually on top of the PPy layer surface (sodium membrane over the electrode labelled 4 and potassium membrane over the electrode labelled 5 as shown in Fig. 2A), and kept then in air overnight at room temperature in order to evaporate the solvent. They were subsequently hydrated in PBS buffer for at least $24 \mathrm{~h}$ before use and always stored in the same solution. Fig. 2A.3 shows the SEM image of electrode labelled 4 covered by the sodium membrane.

Calibration curves were obtained by adding successive aliquots of sodium or potassium nitrate solutions (prepared with a concentration range of $1-10^{-5} \mathrm{M}$ by serial dilution) under magnetic stirring, to increase the concentration of the anion from $10^{-8} \mathrm{M}$ to $10^{-1} \mathrm{M}$ in a calibration buffer of $25 \mathrm{~mL}$. The $\mu$ ISE produce a potential which is related to the activity of a specific ion in the presence of others. Variations in potential were recorded after stabilization and the value was plotted as a function of the logarithm of the each ion activity which was calculated according to the Debye-Hückel approximation [49].

\subsection{4. $\mathrm{pH}$ sensor development}

For the potentiometric $\mathrm{pH}$ sensor, we implemented the growth of iridium oxide films method described in [32] on the gold electrode with $0.1 \mathrm{~mm}^{2}$ area (electrode labelled 6 in Fig. 2A). The platform was immersed in a solution that contained $\mathrm{IrCl}_{3} \cdot 3 \mathrm{H}_{2} \mathrm{O}$ $(0.2 \mathrm{mM}), \mathrm{H}_{2} \mathrm{C}_{2} \mathrm{O}_{4} \cdot 2 \mathrm{H}_{2} \mathrm{O}(1 \mathrm{mM})$ and $\mathrm{K}_{2} \mathrm{CO}_{3}(5 \mathrm{mM})$ dissolved in distilled water. This solution had been aged at $37^{\circ} \mathrm{C}$ for 4 days and stored at $4{ }^{\circ} \mathrm{C}$ until used. Anodically electrodeposited iridium oxide films (AEIROF) were obtained by a dynamic potential sweep method consisting of 50 potential sweeps between open circuit potential (near $0.0 \mathrm{~V}$ ) and $0.6 \mathrm{~V}$ at scan rate of $10 \mathrm{mV} \mathrm{s}^{-1}$. The response of the AEIROF $\mathrm{pH}$ sensor was studied in terms of open circuit potential evolution over a $\mathrm{pH}$ range between 2 and 11 . The sensor was calibrated in PBS buffer and also in AU samples. The $\mathrm{pH}$ was modified under mechanical stirring, by serial addition of either $\mathrm{NaOH}$ or $\mathrm{HCl}$. The $\mathrm{pH}$ changes were monitored in parallel using a commercial pH-meter. 


\subsection{Experimental procedure}

The experimental validation of the platform was done in three different samples: in controlled buffer, AU and in RU. AU was prepared according to [50]. Table S1 (Supporting Information) shows the concentration values selected for the used AU.

For the extraction of the RU, 9-week old C57B6 male mice were housed in metabolic cages and fed gel food formulated to contain standard amounts of sodium and potassium $\left(\mathrm{Na}^{+} 0.3 \%, \mathrm{~K}^{+} 0.8 \%\right.$, $\mathrm{Cl}^{-} \mathbf{0 . 3 7 \%}$, Control) [51]. Urine was collected daily under a layer of mineral oil to prevent evaporation in sterile containers. On the third day, mice were divided in four groups: one was kept on Control diet; the others were switched to one of three experimental diets containing high levels of sodium $(\mathrm{NaCl} 4 \%$, HighNa), potassium $(\mathrm{KCl} 4 \%$, HighK), or both $(\mathrm{NaCl} 4 \%, \mathrm{KCl} 4 \%$, HighNaK). Urine was collected for two extra days. All samples were kept frozen until analyzed. Experimental procedures were revised and approved by our local animal research ethics committee (CEAEA, Universidad de Zaragoza, Spain).

For the experimental measurement of the urine ion compounds, the samples were diluted 1:100 in distilled deionized water and inserted by microfluidic channels in the developed multisensory platform. In order to correlate the obtained measurement of the multisensor, the ion concentrations in biological samples were also measured with an Atomic Spectrometer, in this case, urine was diluted 1:5000 in $5 \mathrm{mM} \mathrm{CsCl}$ solution. Concentrations of $\mathrm{Na}^{+}$and $\mathrm{K}^{+}$in the diluted samples were determined by flame photometry against appropriate standards prepared in the same diluent. Linear fit of the standard values was employed to calculate absolute ion concentrations in the biological samples, after correction for dilution. Each individual sample was quantified in duplicate. Results are shown as the average of 2 mice exposed to a particular experimental diet.

\section{Results and discussion}

In this work the best way to integrate all sensors optimizing the electrode modification step by step was carefully studied in order to reduce interferences between processes. Most of the published multiparametric focus on individual sensor preparation and characterization, without taking into account the presence of the other sensors lacking a prove of validity [52,53]. Three different electrodepositions processes were required for the development of all the sensors, as shown in Fig. 2B. Silver electrodeposition was selected as the first one in order to not affect the other sensors by its immersion in the silver solution, and subsequent cleaning in concentrated ammonia and nitric acid. Then, a PPy layer was electrodeposited, leaving the electrodeposition of IrOx as the last electrodeposition process. IrOx is the most delicate layer and it is necessary to avoid its contact with the other solutions. The last step was the manual deposition of sub-microlitre volumes of the three membranes $\left(\mathrm{Na}^{+}, \mathrm{K}^{+}\right.$and PVB) (Fig. 2B). Furthermore, big efforts were done to find the best working conditions, taking into account their preparation, optimization, calibration and storage, which benefit all the sensors included in the platform. In the following sections, the study of individual optimum working conditions for either sensor, and its relation with the rest of the system is presented. PBS was the selected medium to store the sensors due to its composition rich in $\mathrm{NaCl}$ and $\mathrm{KCl}$. These ions are adequate to keep the $\mu$ ISE membranes and the high quantity of chloride $\left(\mathrm{Cl}^{-}\right)$ helps the PVB membrane to have a stable $\mathrm{Cl}^{-}$concentration for maintaining the $\mathrm{Ag} / \mathrm{AgCl}$ stable reference electrode. Also, PBS is a good buffer to store the IrOx sensor of $\mathrm{K}^{+}$is required to keep their electrodeposited film stable.

\subsection{Platform calibration in buffer}

In order to check the correct response of the microelectrodes after the cleaning and activation process detailed in section 2.4, $\mathrm{CV}$ were carried out in static and dynamic conditions. Fig. S1A (Supporting Information) shows the response of the different microelectrode dimensions in ferro/ferricyanide $\left(10^{-2} \mathrm{M}\right)$ solution. Fig. S1C (Supporting Information) shows typical CV responses of gold electrodes at different scan rates for static conditions. All the voltammograms show consistent peak current $\left(\mathrm{I}_{\mathrm{p}}\right)$ values when compared with the state currents predicted by Randles-Sevcik [54] as shown in Fig. S1E (Supporting Information). Also, the gold microelectrodes were tested in dynamic conditions at different flow rates. In this case the voltammograms of Fig. S1 B and D (Supporting Information) presented the expected sigmoidal shape, with a consistent limiting current $\left(\mathrm{I}_{\lim }\right)$ values compared with Levich's equation [55]. There is a lower limit for the flow rate $(<25 \mu \mathrm{L} / \mathrm{min})$ under which the current deviate from theory. This is because axial diffusion becomes significant [56]. The $\Delta$ Ep obtained was $59 \mathrm{mV}$ as a reversible electrode kinetics behavior [37].

\subsubsection{DO calibration}

The amperometric DO response was studied as in our previous work, where it was also stated that activation of the sensor was needed before its calibration [35]. In this work, the sensor was calibrated using external $\mathrm{CE}$ and $\mathrm{RE}$ and compared with the integrated $\mathrm{CE}$ and $\mathrm{pRE}$ configuration. The comparison of reduction potentials using both electrodes configurations was studied as shown in Fig. S2A (Supporting Information). The final selected potential was $-850 \mathrm{mV}$ for the calibration measurement of the DO concentration. Fig. S2 B (Supporting Information) shows the calibration curve of the polarized current measured for eight different DO concentrations in the range between 0 and $8 \mathrm{mg} \mathrm{L}^{-1}$. The sensor exhibited a good performance, displaying excellent linearity in all the DO concentration range. DO sensor exhibited a sensitivity of $3.60 \pm 0.2 \mathrm{nA}\left(\mathrm{mg} \mathrm{L}^{-1}\right)$ and a correlation factor of 0.995 using the integrated three electrodes configuration. LOD and LOQ were also estimated, resulting in $0.11 \pm 0.02 \mathrm{mg} \mathrm{L}^{-1}$ and $0.38 \pm 0.05 \mathrm{mg} \mathrm{L}^{-1}$ respectively. These results show a good response in a wide range of concentrations with low limit of detection allowing their use for detection of cellular response to some drug, to monitor cell activity and also to control possible bacterial contamination.

\subsection{2. $\mathrm{Na}^{+}$and $\mathrm{K}^{+}$calibration}

The crucial direction in the research over potentiometric sensors has been miniaturization. Sensor miniaturization imposed modification of electrode construction. The simplest arrangement is the use of a conducting polymer material as ion to electron transducer between the sensing electrode and the ion-selective polymeric membrane. The electrodeposition and characterization of the conducting PPy layer is shown in Fig. S3 (Supporting Information). SEM image in Fig. 2A.2 shows the roughness surface of the PPy layer which improves the stability of the overlaying coated membrane.

The response of the $\mu$ ISEs was studied for three different plasticizers (DOS, o_NPOE, DBP). Fig. S4 (Supporting Information) shows the response with the different membranes composition. We selected the plasticizer that provided the best results in terms of sensitivity, linear range and LOD. For the $\mathrm{Na}^{+}$sensor, the membrane prepared with DOS as plasticizer gave the best behaviour, resulting a Nerstian response of $57 \pm 1 \mathrm{mV}$ decade $^{-1}$, with linear response to the activity of sodium ions over the range $1 \times 10^{-5} \mathrm{M}$ to $1 \times 10^{-1} \mathrm{M}$. The LOD was determined from the intersection of the two extrapolated segments of calibration plots. The use of DOS plasticizer gave a LOD of $5 \times 10^{-6} \mathrm{M}$, which was about one logarithmic unit better compared with the other two plasticizers. The presence of this additive in the selective membrane increases the sensitivity and LOD of 
Table 1

Specification of the $\mu$ ISE sensors using the best plasticizer response; DOS for $\mathrm{Na}^{+}$ membrane and DBP for $\mathrm{K}^{+}$membrane.

\begin{tabular}{lll}
\hline & $\mathrm{Na}^{+} \mu \mathrm{ISE}(\mathrm{n}=10)$ & $\mathrm{K}^{+} \mu \mathrm{ISE}(\mathrm{n}=10)$ \\
\hline Sensitivity & $57 \pm 1 \mathrm{mV}$ decade & $52 \pm 2 \mathrm{mV}$ decade \\
Detection Limit & $5 \times 10^{-6} \mathrm{M}$ & $0.5 \times 10^{-5} \mathrm{M}$ \\
Measuring range & $1 \times 10^{-5} \mathrm{M}-1 \times 10^{-1} \mathrm{M}$ & $8 \times 10^{-5} \mathrm{M}-1 \times 10^{-1} \mathrm{M}$ \\
pH range & $3-12$ & $3-12$ \\
Selectivity coefficient & $-2.31\left(\mathrm{~K}^{+}\right)$ & $-2.11\left(\mathrm{Na}^{+}\right)$ \\
$\log \left(\mathrm{K}_{\text {ion }, \mathrm{M}}^{\text {pot }}\right)$ & $-2.33\left(\mathrm{Li}^{+}\right)$ & $-2.45\left(\mathrm{Li}^{+}\right)$ \\
& $-4.41\left(\mathrm{Ca}^{2+}\right)$ & $-3.69\left(\mathrm{Ca}^{2+}\right)$ \\
& $-4.41\left(\mathrm{Mg}^{2+}\right)$ & $-3.75\left(\mathrm{Mg}^{2+}\right)$ \\
Response time & $<5 \mathrm{~s}$ & $<5 \mathrm{~s}$ \\
Life Time & $>3 \mathrm{months}$ & $>3 \mathrm{months}$ \\
\hline
\end{tabular}

the membrane to $\mathrm{Na}^{+}$changes compared with the other used plasticizers, by reducing the interference [57]. For the $\mathrm{K}^{+}$membrane, the best performance was obtained with the use of the DBP membrane. In this case, the resulting sensitivity was $52 \pm 2 \mathrm{mV} \mathrm{decade}^{-1}$ and presented a linear response range from $8 \times 10^{-5} \mathrm{M}$ to $1 \times 10^{-1} \mathrm{M}$ with a LOD of $0.5 \times 10^{-5} \mathrm{M}$. That means that the sensors cannot recognize concentration changes lower than the LOD. The obtained LOD were enough to use the developed $\mu$ ISE in our application for detect in real-time concentrations of sodium and potassium in mice urine fed with different diets.

After the selection of the best membrane, both sensors were studied in terms of sensitivity, LOD, measuring range, $\mathrm{pH}$ range, selectivity coefficients, response time and life time. Table 1 summarizes the characteristics of the sensors response. These results are comparable with other previously described, as shown in Table S2 (Supporting Information). The response time of the $\mu$ ISEs is presented in Fig. S5 (Supporting Information). The microelectrodes reached the equilibrium response in a very short period of about $5 \mathrm{~s}$, faster than other reported $\mu$ ISE shown in Table 2 (Supporting Information). This improvement in the response time was achieved through the PPy $\left[3,3^{\prime}-\mathrm{Co}\left(1,2-\mathrm{C}_{2} \mathrm{~B}_{9} \mathrm{H}_{11}\right)_{2}\right]$ layer due its high ion-transfer and mobility between the adjacent solution and the polymer matrix [31]. The potential response of the microelectrode was not influenced in the $\mathrm{pH}$ range between 3 and 12 as shown in Fig. S6 (Supporting Information). Outside this pH range, the ionophore complex in the membrane behaves as an anionexchanger and what is sensed is the chloride anion or the hydroxide anion [58].

The selectivity is clearly one of the most important characteristics of this type of sensors determining if a reliable measurement in a real sample is possible. An ideally selective ionophore interacts only with the target analyte, avoiding any stabilization of an interfering ion in the membrane $[59,60]$. The potentiometric selectivity coefficients $\left(\mathrm{K}_{\mathrm{ion}, \mathrm{M}}^{\mathrm{pot}}\right)$ of our $\mu$ ISE were evaluated using the matched potential method (MPM) [61]. The $\log \left(\mathrm{K}_{\mathrm{ion}, \mathrm{M}}^{\mathrm{pot}}\right)$ values for $\mathrm{Na}^{+}$and $\mathrm{K}^{+}$ membranes are presented in Table 1. Fig. S7 (Supporting Information) presents the experimental plots. These values are comparable to those reported in the literature as shown in Table S2 (Supporting Information).
Finally, Fig. S8 (Supporting Information) shows the evolution of the sensitivity of each type of $\mu$ ISE during three months. During this time, the microelectrodes exhibited a Nerstian response with a reduction of about $15 \%$ for both $\mu$ ISE after the third week. The microsensors remained without any further degradation of their response during the next month demonstrating the good behaviour of the PPy layer, which increases the stability of the microelectrodes.

\subsection{3. pH calibration}

IrOx films were prepared by electrochemical techniques, generating hydrated IrOx layers where the $\mathrm{pH}$ sensitivity depends on the oxidation state of the IrOx [62]. In these cases the obtained sensitivities are greater than $59 \mathrm{mV}$ decade $^{-1}$, meaning the transduction mechanism involves more hydrogen ions than the transferred electrons in the redox reaction. For this reason, just after IrOx film electrodeposition, the sensor was stored in PBS during $24 \mathrm{~h}$ for conditioning purposes. The sensor was calibrated with the integrated pRE exhibiting a linear super-Nerstian response between $\mathrm{pH}$ ranging from 2 to 11 , with an average slope of $69 \pm 1 \mathrm{mV}$ decade $^{-1}$ $(n=5)$. Fig. S9A (Supporting Information) shows the calibration curve. The response time of the sensor was very fast $(<5 s)$. The obtained results were comparable with previously published response time, linear $\mathrm{pH}$ range and slope values [63], and were adequate for the determination of $\mathrm{pH}$ in the experimental urine. Long term stability was measured on AEIROF sensors stored at room temperature and immersed in $\mathrm{PBS}$ at $\mathrm{pH}$ 7. Calibration curves recorded every 5 days over a month (Supporting Information Fig. S9B) show sensor sensitivity remained constant after the fifth day with a deviation of $\pm 2 \mathrm{mV}$.

\subsection{Platform calibration in artificial urine}

The platform was first validated in AU samples. AU is a solution of water mixed with different organic and inorganic components like urea, creatinine, uric acid, chlorides, sulfates, phosphates,etc, widely used for studies and developments in scientific research [50]. Main advantages of an artificial solution over real urine is the control over its composition, a longer shelf-life and easier storage. All this facilitates the use of this solution to test our integrated multielectrode platform before its validation in real samples.

The $\mu$ ISE were calibrated in nitrate mediums (as shown in Section 3.1.2) and also in chloride mediums using the integrated pRE in order to validate its functionality. In both mediums they exhibited a good performance as shown in Fig. 3 demonstrating that the sensitivities were not influenced by the change in the medium. Six different AU solutions containing different ion molarity were used for the development of the calibration curves. Obtained sensitivities were in good agreement with the results obtained in the buffer calibration mediums.

The $\mathrm{pH}$ electrode was also calibrated in the AU medium, where the $\mathrm{pH}$ was modified by additions of $\mathrm{HCl}$ or $\mathrm{NaOH}$. Fig. S9A (Supporting Information) shows that the sensor exhibited a linear response in a $\mathrm{pH}$ range between 3 and 9 , and was not influenced by the matrix

Table 2

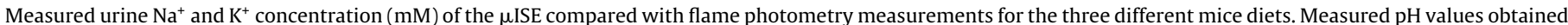
with the custom AEIROF sensor.

\begin{tabular}{|c|c|c|c|c|c|c|c|c|c|c|}
\hline & \multicolumn{5}{|l|}{ DAY 1} & \multicolumn{5}{|l|}{ DAY 4} \\
\hline & \multicolumn{2}{|l|}{$\mathrm{Na}^{+}(\mathrm{mM})$} & \multicolumn{2}{|l|}{$\mathrm{K}^{+}(\mathrm{mM})$} & \multirow[t]{2}{*}{$\mathrm{pH}$} & \multicolumn{2}{|l|}{$\mathrm{Na}^{+}(\mathrm{mM})$} & \multicolumn{2}{|l|}{$\mathrm{K}^{+}(\mathrm{mM})$} & \multirow[t]{2}{*}{$\mathrm{pH}$} \\
\hline & $\begin{array}{l}\text { Flame } \\
\text { Photometry }\end{array}$ & $\mu$ ISE Platform & $\begin{array}{l}\text { Flame } \\
\text { Photometry }\end{array}$ & $\mu I S E$ Platform & & $\begin{array}{l}\text { Flame } \\
\text { Photometry }\end{array}$ & $\mu$ ISE Platform & $\begin{array}{l}\text { Flame } \\
\text { Photometry }\end{array}$ & $\mu I S E$ Platform & \\
\hline Sodium diet & 88.7 & $90.2 \pm 0.3$ & 233.4 & $235.2 \pm 0.4$ & $6.9 \pm 0.3$ & 408.2 & $418.2 \pm 0.2$ & 152.6 & $148.5 \pm 0.6$ & $7.2 \pm 0.3$ \\
\hline Potassium diet & 62.3 & $63.4 \pm 0.4$ & 206.4 & $206.8 \pm 0.5$ & $6.8 \pm 0.2$ & 41.3 & $43.3 \pm 0.3$ & 341.6 & $344.8 \pm 0.5$ & $7.1 \pm 0.3$ \\
\hline Mixed diet & 50.8 & $53.2 \pm 0.4$ & 212.5 & $213.4 \pm 0.5$ & $6.8 \pm 0.2$ & 272.2 & $275.2 \pm 0.3$ & 271.9 & $279.8 \pm 0.4$ & $6.9 \pm 0.2$ \\
\hline
\end{tabular}



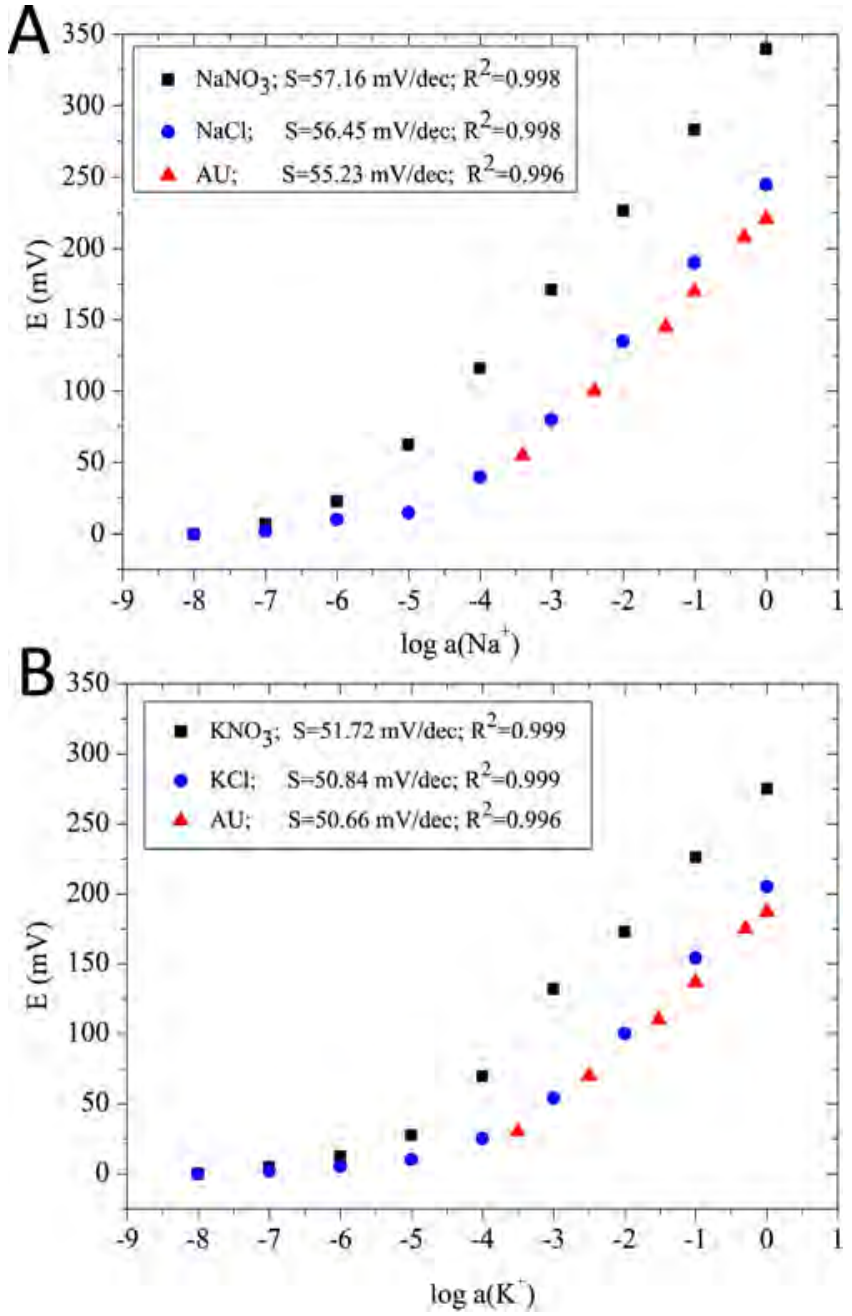

Fig. 3. Potentiometric response of the $\mu$ ISE at different ion concentration in $\mathrm{Cl}^{-}$and $\mathrm{NO}_{3}$ medium and artificial urine for A) $\mathrm{Na}^{+}$membrane and B) $\mathrm{K}^{+}$membrane.

components of the urine. In terms of sensibility measures in AU did not alter the values, obtaining a value of $68 \mathrm{mV}$ decade $^{-1}$.

\subsection{Analysis of real urine samples}

The determination of ion compounds in biological samples is a challenging task. Beyond the selectivity required, the sensors must be impervious to unspecific interferences, such as biofouling, due to the attachment of components of the matrix onto the sensing membranes, which may result in significant signal drift and even permanent damage [64]. In order to reduce these unspecific interferences [65], each RU was diluted with deionized water 1:100 before being measured.

The samples used for analyzing $\mathrm{Na}^{+}, \mathrm{K}^{+}$and $\mathrm{pH}$ were obtained from different mice fed with special diet of sodium, potassium or mixed sodium/potassium. The measurements were done with the urine samples collected the first day, before starting the special diet, and with the ones collected the fourth day [51]. To perform the ion determination, sensors were first calibrated in $\mathrm{AU}$ as shown in the previous section. A small volume sample $(0.83 \mu \mathrm{L})$ was enough to fill the sensing chamber. Open circuit potentials were recorded each second, during 80-90 s for each $\mu$ ISE and $\mathrm{pH}$ sensor as shown in Fig. 4. The same measurement was repeated three times. Using the mean value of the recorded potentials, we extracted the ion activity. Deviations in the registered potential were neglected since uncertainty in the activities came mainly from the interpolation.
We have calculated the interpolation error using the standard deviation formula of propagation of uncertainty with a calibration curve [66]. From the obtained activities, we calculated the corresponding concentration values using Debye-Hückel limiting law and approximating the ion strength value from the AU compounds.

As can be seen in Fig. 4, each specific diet basically changed the ion concentration between the first and the fourth day. Concretely, in the case of the mouse with a sodium diet, the concentration of $\mathrm{Na}^{+}$in the urine increased 4.7 times. In this urine, $\mathrm{K}^{+}$concentration decreased 1.6 times its initial value. When mice were fed a high potassium diet, the opposite behavior just happened. $\mathrm{Na}^{+}$concentration was reduced 1.5 times from day 1 to day 4 , whereas $\mathrm{K}^{+}$ concentration increased 1.6 times. These changes were as expected due to the mechanisms employed by the kidney to regulate final urinary excretion of $\mathrm{Na}^{+}$and $\mathrm{K}^{+}$.

Potassium secretion in the collecting duct is achieved at the expense of reabsorbing sodium, a process stimulated by hormone aldosterone. An excess dietary sodium is excreted by inhibiting aldosterone secretion and reducing collecting duct sodium reabsorption, which in turn reduces potassium secretion. Table 2 shows the measured $\mathrm{Na}^{+}$and $\mathrm{K}^{+}$concentrations for the three different diets using the integrated $\mu$ ISE multi-sensors are in good agreement with those obtained by flame photometry [51]. Deviations in the concentration values obtained between both techniques can be explained due to the effect of different ions present in the urine, which can interfere with the measurement of the analyte of interest. There is also an indeterminate error due to the approximation of the ionic strength used to determine the concentration values from the obtained activities of the $\mu$ ISE. Thus, our $\mu$ ISE sensors have demonstrated enough sensitivity and specificity to work satisfactorily over a broad range of physiological and pathological values. Although the ion interference is less of a problem with atomic spectroscopy, our work demonstrates that ISE sensors are advantageous for real time monitoring of ion concentrations in complex biological matrixes. $\mu$ ISE sensors are also far more affordable that atomic spectroscopy, which in addition generally requires higher sample volumes that those employed in the current work. Ion concentration monitoring will be instrumental for the realization of 3D organotypic culture of epithelia based organs, such as the kidney, or reproducing excitable tissues.

Finally, Table 2 also details the $\mathrm{pH}$ values recorded for each sample using the AEIROF pH sensor. As can be seen, the type of diet did not affect the urine $\mathrm{pH}$, maintaining values between $6.8-7.2 \mathrm{pH}$, which is a normal urinary $\mathrm{pH}$. The measurement of $\mathrm{pH}$ complemented that of oxygen, allowing the investigation of the metabolic state of cells in the system. For instance, proliferative cells, including cancer cells but also most mammal cells in culture, exhibit glycolytic metabolism, while the physiological metabolism in vivo is determined by oxidative phosphorylation in the mitochondria. Determining oxygen consumption and acidification by lactic acid production is a well-established method to estimate the type of predominant energy metabolism.

\section{Conclusions}

This work describes the fabrication and validation of a multisensing platform embedded in a versatile and low-cost microfluidic device. The platform integrates all the necessary microelectrodes for the electrochemical measurement of $\mathrm{DO}, \mathrm{Na}^{+}, \mathrm{K}^{+}$and $\mathrm{pH}$. Simultaneous measurement of four biologically relevant parameters in small sample volume $(0.83 \mu \mathrm{L})$, either static or in-line with microfluidic cell culture devices clearly distinguish our device from previous systems.

The problem of integration of four different sensors was solved through adequate platform design and fabrication protocols. We 

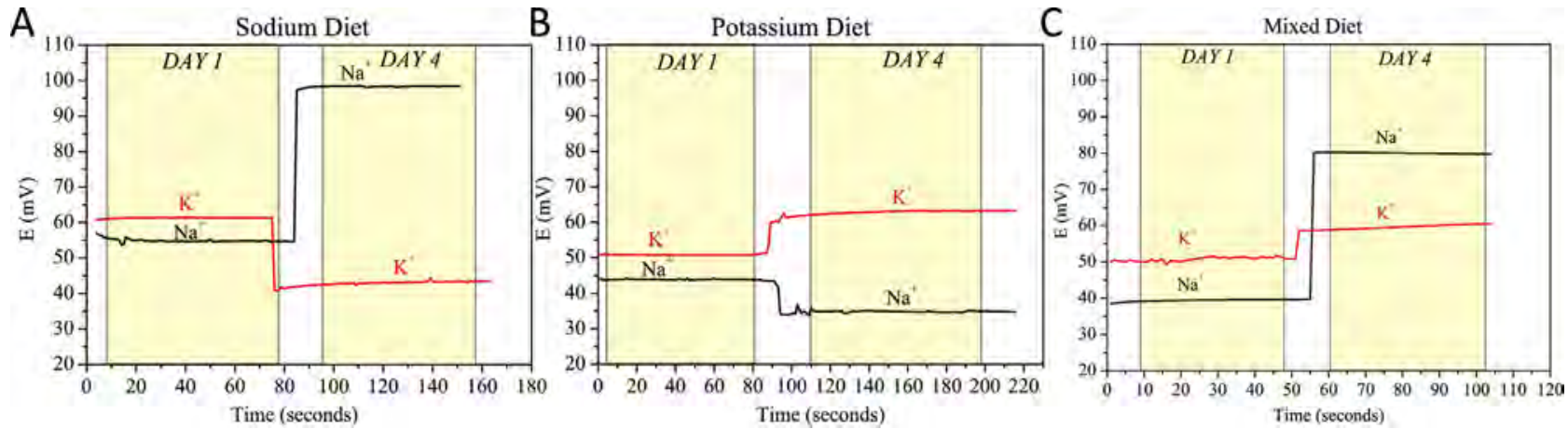

Fig. 4. Potentiometric response of $\mathrm{Na}^{+}$and $\mathrm{K}^{+} \mu$ ISE of mouse urine with $\mathrm{A}$ ) a sodium diet, B) a potassium diet and C) a mixed diet.

found, PBS was the best buffer to store the sensors while maintaining their best performance. The four types of sensors exhibited a good behaviour towards linear response in a wide range of concentrations, with low LOD, high sensitivity, rapid response time and long lifetime. The DO sensor showed a sensitivity of $3.60 \pm 0.2$ $\mathrm{nA}\left(\mathrm{mg} \mathrm{L}^{-1}\right)$ in a wide range of concentrations, with a LOD and LOQ of $0.11 \pm 0.02 \mathrm{mg} \mathrm{L}^{-1}$ and $0.38 \pm 0.05 \mathrm{mg} \mathrm{L}^{-1}$ respectively. For the $\mu$ ISE, the use of $\mathrm{PPy}\left[3,3^{\prime}-\mathrm{Co}\left(1,2-\mathrm{C}_{2} \mathrm{~B}_{9} \mathrm{H}_{11}\right)_{2}\right]$ as an internal contact layer between the polymeric sensitive membrane and the gold substrate provided good performance allowing a good ion-transfer and long term potential stability. $\mathrm{Na}^{+}$and $\mathrm{K}^{+} \mu$ ISE exhibited sensitivities of $57 \pm 1 \mathrm{mV}$ decade $^{-1}$ and $52 \pm 2 \mathrm{mV}$ decade $^{-1}$ respectively, in a wide liner range, from $10^{-5} \mathrm{M}$ to $10^{-4} \mathrm{M}$ and low LOD, $5 \times 10^{-6} \mathrm{M}$ and $0.5 \times 10^{-5} \mathrm{M}$ for $\mathrm{Na}^{+}$and $\mathrm{K}^{+} \mu$ ISE respectively. The $\mathrm{pH}$ sensor, prepared by electrochemical deposition of IrOx, exhibited a sensitivity of $69 \pm 1 \mathrm{mV}$ decade ${ }^{-1}$ with a linear response between $\mathrm{pH} 2$ and 11 . DO sensor showed long life times providing by the sensors reactivated before use.

Concentrations of $\mathrm{Na}^{+}, \mathrm{K}^{+}$and $\mathrm{pH}$ were successfully determined in $\mathrm{AU}$ samples. As a proof-of-concept, the usefulness of the platform was also demonstrated in RU samples, where the values were in good agreement with those obtained by flame photometry. So, the fabrication and operation of different sensors within the same platform has been demonstrated, overcoming the use of several commercial sensors at the same time in terms of cost, time, simplicity and versatility principally.

\section{Acknowledgements}

This work was partially done with the support of the Spanish government funded projects DPI2011-28262-C04 and DPI2015-65401-C3-3-R (MINECO/FEDER, EU) and BFU2007-62119 (MINECO). Also, the authors acknowledge the financial support from the European Union's Horizon 2020 research and innovation programe entitled MicroMole and HEARTEN grant agreement No 653626 and No 643694 respectively. The authors also acknowledge ICTS "NANBIOSIS", more specifically by the SU8 Unit of the CIBER in Bioengineering, Biomaterials \& Nanomedicne (CIBER-BBN) at the IMB-CNM (CSIC). This work has also made use of the Spanish ICTS Network MICRONANOFABS partially supported by MEINCOM.

\section{Appendix A. Supplementary data}

Supplementary data associated with this article can be found, in the online version, at http://dx.doi.org/10.1016/j.snb.2017.09.104.

\section{References}

[1] Y.S. Zhang, A. Khademhosseini, Seeking the right context for evaluating nanomedicine: from tissue models in petri dishes to microfluidic organs-on-a-chip, Nanomedicine 10 (2015) 685-688, http://dx.doi.org/10. 2217/nnm.15.18.

[2] M. Baker, Tissue models: a living system on a chip, Nature 471 (2011) 661-665, http://dx.doi.org/10.1038/471661a.

[3] D. Huh, G.A. Hamilton, D.E. Ingber, From three-dimensional cell culture to Organs-on-Chips, Trends Cell Biol. 21 (2011) 745, http://dx.doi.org/10.1016/j. tcb.2011.09.005.

[4] A. Perestrelo, A. Águas, A. Rainer, G. Forte, Microfluidic Organ/Body-on-a-Chip devices at the convergence of biology and microengineering, Sensors 15 (2015) 31142-31170, http://dx.doi.org/10.3390/s151229848.

[5] E.R. Shamir, A.J. Ewald, Three-dimensional organotypic culture: experimental models of mammalian biology and disease, Nat. Rev. Mol. Cell Biol. 15 (2014) 647-664, http://dx.doi.org/10.1038/nrm3873.

[6] K.-J. Jang, A.P. Mehr, G.A. Hamilton, L.A. McPartlin, S. Chung, K.-Y. Suh, D.E. Ingber, Human kidney proximal tubule-on-a-chip for drug transport and nephrotoxicity assessment, Integr. Biol. 5 (2013) 1119, http://dx.doi.org/10. 1039/c3ib40049b.

[7] K.-J. Jang, K.-Y. Suh, A multi-layer microfluidic device for efficient culture and analysis of renal tubular cells, Lab Chip. 10 (2010) 36-42, http://dx.doi.org/10. 1039/B907515A.

[8] M.-H. Wu, S.-B. Huang, G.-B. Lee, Microfluidic cell culture systems for drug research, Lab. Chip. 10 (2010) 939, http://dx.doi.org/10.1039/b921695b.

[9] F. Zheng, F. Fu, Y. Cheng, C. Wang, Y. Zhao, Z. Gu, Organ-on-a-Chip systems microengineering to biomimic living systems, Small 12 (2016) 2253-2282, http://dx.doi.org/10.1002/smll.201503208.

[10] V. Marx, Tissue engineering: organs from the lab, Nature 522 (2015) 373-377, http://dx.doi.org/10.1038/522373a.

[11] R. Toczyłowska-Mamińska, A. Lewenstam, K. Dołowy, Multielectrode bisensor system for time-resolved monitoring of ion transport across an epithelial cell layer, Anal. Chem. 86 (2014) 390-394, http://dx.doi.org/10.1021/ac403808f.

[12] D. Bavli, S. Prill, E. Ezra, G. Levy, M. Cohen, M. Vinken, J. Vanfleteren, M. Jaeger, Y. Nahmias, Real-time monitoring of metabolic function in liver-on-chip microdevices tracks the dynamics of mitochondrial dysfunction, Proc. Natl. Acad. Sci. 113 (2016) E2231-E2240, http://dx.doi.org/10.1073/pnas. 1522556113.

[13] S.E. Eklund, D. Taylor, E. Kozlov, A. Prokop, D.E. Cliffel, A microphysiometer for simultaneous measurement of changes in extracellular glucose, lactate, oxygen, and acidification rate, Anal. Chem. 76 (2004) 519-527, http://dx.doi. org/10.1021/ac034641z.

[14] F. Hafner, Cytosensor Microphysiometer: technology and recent applications, Biosens. Bioelectron. 15 (2000) 149-158.

[15] J.R. McKenzie, A.M. Palubinsky, J.E. Brown, B. McLaughlin, D.E. Cliffel, Metabolic multianalyte microphysiometry reveals extracellular acidosis is an essential mediator of neuronal preconditioning, ACS Chem. Neurosci. 3 (2012) 510-518, http://dx.doi.org/10.1021/cn300003r.

[16] M. Lehmann, W. Baumann, M. Brischwein, H.-J. Gahle, I. Freund, R. Ehret, S. Drechsler, H. Palzer, M. Kleintges, U. Sieben, B. Wolf, Simultaneous measurement of cellular respiration and acidification with a single CMOS ISFET, Biosens. Bioelectron. 16 (2001) 195-203, http://dx.doi.org/10.1016/ S0956-5663(01)00123-3.

[17] S.M. Bonk, M. Stubbe, S.M. Buehler, C. Tautorat, W. Baumann, E.-D. Klinkenberg, J. Gimsa, Design and characterization of a sensorized microfluidic cell-culture system with electro-thermal micro-pumps and sensors for cell adhesion, oxygen, and pH on a glass chip, Biosensors 5 (2015) 513-536, http://dx.doi.org/10.3390/bios5030513.

[18] P.-A. Ruffieux, U. von Stockar, I.W. Marison, Measurement of volumetric (OUR) and determination of specific (qO2) oxygen uptake rates in animal cell cultures, J. Biotechnol. 63 (1998) 85-95, http://dx.doi.org/10.1016/S01681656(98)00046-7.

[19] J.C. Owicki, J. Wallace Parce, Biosensors based on the energy metabolism of living cells: the physical chemistry and cell biology of extracellular acidification, Biosens. Bioelectron. 7 (1992) 255-272, http://dx.doi.org/10. 1016/0956-5663(92)87004-9. 
[20] O.T. Guenat, S. Generelli, N.F. de Rooij, M. Koudelka-Hep, F. Berthiaume, M.L. Yarmush, Development of an array of ion-selective microelectrodes aimed for the monitoring of extracellular ionic activities, Anal. Chem. 78 (2006) 7453-7460, http://dx.doi.org/10.1021/ac0609733.

[21] Y. Kong, H. Chen, Y. Wang, S.A. Soper, Fabrication of a gold microelectrode for amperometric detection on a polycarbonate electrophoresis chip by photodirected electroless plating, Electrophoresis 27 (2006) 2940-2950, http://dx.doi.org/10.1002/elps.200500750.

[22] X. Illa, O. Ordeig, D. Snakenborg, A. Romano-Rodríguez, R.G. Compton, J.P. Kutter, A cyclo olefin polymer microfluidic chip with integrated gold microelectrodes for aqueous and non-aqueous electrochemistry, Lab. Chip. 10 (2010) 1254-1261, http://dx.doi.org/10.1039/B926737A.

[23] S. Metz, R. Holzer, P. Renaud, Polyimide-based microfluidic devices, Lab. Chip. 1 (2001) 29-34, http://dx.doi.org/10.1039/b103896f.

[24] V.V. Cosofret, M. Erdosy, T.A. Johnson, R.P. Buck, R.B. Ash, M.R. Neuman, Microfabricated sensor arrays sensitive to $\mathrm{pH}$ and $\mathrm{K}+$ for ionic distribution measurements in the beating heart, Anal. Chem. 67 (1995) 1647-1653, http:// dx.doi.org/10.1021/ac00106a001.

[25] E. Lindner, R.P. Buck, Microfabricated potentiometric electrodes and their In vivo applications, Anal. Chem. 72 (2000) 336 A-345 A, http://dx.doi.org/10 1021/ac002805v.

[26] F.J. del Campo, Miniaturization of electrochemical flow devices: a mini-review, Electrochem. Commun. 45 (2014) 91-94, http://dx.doi.org/10 1016/j.elecom.2014.05.013.

[27] M.J. González-Guerrero, J.P. Esquivel, D. Sánchez-Molas, P. Godignon, F.X Muñoz, F.J. del Campo, F. Giroud, S.D. Minteer, N. Sabaté, Membraneless glucose/O2 microfluidic enzymatic biofuel cell using pyrolyzed photoresist film electrodes, Lab. Chip. 13 (2013) 2972-2979, http://dx.doi.org/10.1039/ c3lc50319d.

[28] E.M. Zahran, A. New, V. Gavalas, L.G. Bachas, Polymeric plasticizer extends the lifetime of PVC-membrane ion-selective electrodes, The Analyst 139 (2014) 757-763, http://dx.doi.org/10.1039/C3AN01963B.

[29] U. Oesch, D. Ammann, W. Simon, Ion-selective membrane electrodes for clinical use, Clin. Chem. 32 (1986) 1448-1459.

[30] L.F. Ramos-De Valle, Principles of polymer processing, in: E. Saldivar-Guerra, E. Vivaldo-Lima (Eds.), Handb. Polym. Synth. Charact. Process, John Wiley \& Sons, Inc., 2013, pp. 451-461.

[31] A. Cadogan, Z. Gao, A. Lewenstam, A. Ivaska, D. Diamond, All-solid-state sodium-selective electrode based on a calixarene ionophore in a poly(vinyl chloride) membrane with a polypyrrole solid contact, Anal. Chem. 64 (1992) 2496-2501, http://dx.doi.org/10.1021/ac00045a007.

[32] A.M. Cruz, L. Abad, N.M. Carretero, J. Moral-Vico, J. Fraxedas, P. Lozano, G. Subías, V. Padial, M. Carballo, J.E. Collazos-Castro, N. Casañ-Pastor, Iridium oxohydroxide, a significant member in the family of iridium oxides. stoichiometry, characterization, and implications in bioelectrodes, J. Phys. Chem. C. 116 (2012) 5155-5168, http://dx.doi.org/10.1021/jp212275q.

[33] W.-D. Huang, H. Cao, S. Deb, M. Chiao, J.C. Chiao, A flexible pH sensor based on the iridium oxide sensing film, Sens. Actuators Phys. 169 (2011) 1-11, http:// dx.doi.org/10.1016/j.sna.2011.05.016.

[34] P.E. Oomen, M.D. Skolimowski, E. Verpoorte, Implementing oxygen control in chip-based cell and tissue culture systems, Lab. Chip. 16 (2016) 3394-3414 http://dx.doi.org/10.1039/c6lc00772d.

[35] A. Moya, X. Guimerà, F.J. del Campo, E. Prats-Alfonso, A.D. Dorado, M. Baeza, R Villa, D. Gabriel, X. Gamisans, G. Gabriel, Profiling of oxygen in biofilms using individually addressable disk microelectrodes on a microfabricated needle, Microchim. Acta. 182 (2014) 985-993, http://dx.doi.org/10.1007/s00604-014 1405-4.

[36] L.M. Fischer, M. Tenje, A.R. Heiskanen, N. Masuda, J. Castillo, A. Bentien, J Émneus, M.H. Jakobsen, A. Boisen, Gold cleaning methods for electrochemical detection applications, Microelectron. Eng. 86 (2009) 1282-1285, http://dx. doi.org/10.1016/j.mee.2008.11.045.

[37] A.J. Bard, L.R. Faulkner, Electrochemical Methods: Fundamentals and Applications, Wiley, New York, 2001

[38] X. Jin, J. Lu, P. Liu, H. Tong, The electrochemical formation and reduction of a thick $\mathrm{AgCl}$ deposition layer on a silver substrate, J. Electroanal. Chem. 542 (2003) 85-96, http://dx.doi.org/10.1016/S0022-0728(02)01474-2.

[39] T. Guinovart, G.A. Crespo, F.X. Rius, F.J. Andrade, A reference electrode based on polyvinyl butyral (PVB) polymer for decentralized chemical measurements, Anal. Chim. Acta. 821 (2014) 72-80, http://dx.doi.org/10. 1016/j.aca.2014.02.028.

[40] L.C. Clark, R. Wolf, D. Granger, Z. Taylor, Continuous recording of blood oxygen tensions by polarography, J. Appl. Physiol. 6 (1953) 189-193.

[41] L.A. Currie, Limits for qualitative detection and quantitative determination. Application to radiochemistry, Anal. Chem. 40 (1968) 586-593, http://dx.doi. org/10.1021/ac60259a007.

[42] Z. Mousavi, K. Granholm, T. Sokalski, A. Lewenstam, All-solid-state electrochemical platform for potentiometric measurements, Sens. Actuators B Chem. 207 (2015) 895-899, http://dx.doi.org/10.1016/j.snb.2014.06.067.

[43] N. Zine, J. Bausells, F. Teixidor, C. Viñas, C. Masalles, J. Samitier, A. Errachid, All-solid-state hydrogen sensing microelectrodes based on novel PPy[3, 3'-Co(1, 2-C2B9H11)2] as a solid internal contact, Mater. Sci. Eng. C. 26 (2006) 399-404, http://dx.doi.org/10.1016/j.msec.2005.10.073.

[44] C. Masalles, F. Teixidor, S. Borrós, C. Viñas, Cobaltabisdicarbollide anion [Co(C2B9H11)2]- as doping agent on intelligent membranes for ion capture, ]. Organomet. Chem. 657 (2002) 239-246, http://dx.doi.org/10.1016/S0022$328 \mathrm{X}(02) 01432-8$
[45] E. Bakker, P. Bühlmann, E. Pretsch, Carrier-Based ion-selective electrodes and bulk optodes. 1. General characteristics, Chem. Rev. 97 (1997) 3083-3132, http://dx.doi.org/10.1021/cr940394a.

[46] N. Zine, J. Bausells, F. Vocanson, R. Lamartine, Z. Asfari, F. Teixidor, E. Crespo, I.A.M. de Oliveira, J. Samitier, A. Errachid, Potassium-ion selective solid contact microelectrode based on a novel 1,3-(di-4-oxabutanol)-calix[4] arene-crown-5 neutral carrier, Electrochim. Acta 51 (2006) 5075-5079, http://dx.doi.org/10.1016/j.electacta.2006.03.060.

[47] I.A.M. de Oliveira, D. Risco, F. Vocanson, E. Crespo, F. Teixidor, N. Zine, J. Bausells, J. Samitier, A. Errachid, Sodium ion sensitive microelectrode based on a p-tert-butylcalix[4] arene ethyl ester, Sens. Actuators B-Chem. 130 (2008) 295-299, http://dx.doi.org/10.1016/j.snb.2007.08.026.

[48] I.A. Marques de Oliveira, M. Pla-Roca, L. Escriche, J. Casabó, N. Zine, J. Bausells, F. Teixidor, E. Crespo, A. Errachid, J. Samitier, Novel all-solid-state copper(II) microelectrode based on a dithiomacrocycle as a neutral carrier, Electrochim. Acta 51 (2006) 5070-5074, http://dx.doi.org/10.1016/j.electacta.2006.03.042.

[49] P. Debye, E. Hückel, Zur Theorie der Elektrolyte. I. Gefrierpunktserniedrigung und verwandte Erscheinungen, Phys. Z. 24 (1923) 185-206.

[50] S. Chutipongtanate, V. Thongboonkerd, Systematic comparisons of artificial urine formulas for in vitro cellular study, Anal. Biochem. 402 (2010) 110-112, http://dx.doi.org/10.1016/j.ab.2010.03.031.

[51] Y. Lazo-Fernández, G. Baile, P. Meade, P. Torcal, L. Martínez, C. Ibañez, M.L. Bernal, B. Viollet, I. Giménez, Kidney-specific genetic deletion of both AMPK $\alpha$-subunits causes salt and water wasting, Am. J. Physiol. Renal Physiol. 312 (2017) F352-F365, http://dx.doi.org/10.1152/ajprenal.00169.2016.

[52] Z. Xu, Q. Dong, B. Otieno, Y. Liu, I. Williams, D. Cai, Y. Li, Y. Lei, B. Li, Real-time in situ sensing of multiple water quality related parameters using micro-electrode array (MEA) fabricated by inkjet-printing technology (IPT), Sens. Actuators B Chem. 237 (2016) 1108-1119, http://dx.doi.org/10.1016/j. snb.2016.09.040

[53] B. Zhou, C. Bian, J. Tong, S. Xia, Fabrication of a miniature multi-parameter sensor chip for water quality assessment, Sensors 17 (2017), http://dx.doi. org/10.3390/s17010157.

[54] D.K. Roe, Analytical electrochemistry: theory and instrumentation of dynamic techniques, Anal. Chem. 50 (1978) 9-16, http://dx.doi.org/10.1021/ ac50028a002.

[55] R.G. Compton, A.C. Fisher, R.G. Wellington, P.J. Dobson, P.A. Leigh, Hydrodynamic voltammetry with microelectrodes: channel microband electrodes; theory and experiment, J. Phys. Chem. 97 (1993) 10410-10415, http://dx.doi.org/10.1021/j100142a024.

[56] J.A. Alden, R.G. Compton, Hydrodynamic voltammetry with channel microband electrodes: axial diffusion effects, J. Electroanal. Chem. 404 (1996) 27-35, http://dx.doi.org/10.1016/0022-0728(95)04399-3.

[57] H.-J. Kim, J.W. Hummel, S.J. Birrell, Evaluation of nitrate and potassium ion-selective membranes for soil macronutrient sensing, Trans. ASABE. 49 (2006) 597, http://dx.doi.org/10.13031/2013.20476.

[58] S. Kim, H. Kim, K.H. Noh, S.H. Lee, S.K. Kim, J.S. Kim, Potassium ion-selective membrane electrodes based on 1,3-alternate calix[4] crown-5-azacrown-5, Talanta 61 (2003) 709-716, http://dx.doi.org/10.1016/s0039-9140(03)00329-

[59] E. Bakker, P. Bühlmann, E. Pretsch, Polymer membrane ion-selective electrodes-what are the limits? Electroanalysis 11 (1999) 915-933. doi:10.1002/(SICI)1521-4109(199909)11:13<915::AID-ELAN915>3.0.CO;2- .

[60] P.B. Yoshio Umezawa, Potentiometric selectivity coefficients of IonSelective electrodes. part I. Inorganic cations (Technical report), Pure Appl. Chem. 72 (2000) 1851-2082, http://dx.doi.org/10.1351/pac200072101851.

[61] Y. Umezawa, K. Umezawa, H. Sato, Selectivity coefficients for ion-selective electrodes: recommended methods for reporting $K_{\mathrm{A}, \mathrm{B}}{ }^{\text {pot }}$ values (Technical Report), Pure Appl. Chem. 67 (1995) 507-518, http://dx.doi.org/10.1351/ pac199567030507.

[62] W. Olthuis, M.A.M. Robben, P. Bergveld, M. Bos, W.E. van der Linden, pH sensor properties of electrochemically grown iridium oxide, Sens. Actuators B Chem. 2 (1990) 247-256, http://dx.doi.org/10.1016/0925-4005(90)80150-X.

[63] E. Prats-Alfonso, L. Abad, N. Casañ-Pastor, J. Gonzalo-Ruiz, E. Baldrich, Iridium oxide $\mathrm{pH}$ sensor for biomedical applications. Case urea-urease in real urine samples, Biosens. Bioelectron. 39 (2013) 163-169, http://dx.doi.org/10.1016/j. bios.2012.07.022.

[64] P. Bühlmann, M. Hayakawa, T. Ohshiro, S. Amemiya, Y. Umezawa, Influence of natural, electrically neutral lipids on the potentiometric responses of cation-selective polymeric membrane electrodes, Anal. Chem. 73 (2001) 3199-3205, http://dx.doi.org/10.1021/ac0015016.

[65] T. Guinovart, D. Hernández-Alonso, L. Adriaenssens, P. Blondeau, F.X. Rius, P. Ballester, F.J. Andrade, Characterization of a new ionophore-based ion-selective electrode for the potentiometric determination of creatinine in urine, Biosens. Bioelectron. 87 (2017) 587-592, http://dx.doi.org/10.1016/j. bios.2016.08.025.

[66] D.C. Harris, Quantitative Chemical Analysis, edición: 0007, W H Freeman \& Co, New York, 2006

\section{Biographies}

Ana Moya obtained an Engineering of Telecommunications degree from the Universitat Autònoma de Barcelona, Spain, in 2008. She has been working with the Biomedical Application's Group in the Institut de Microelectrònica de Barcelona, 
Centro Nacional de Microelectrónica, (IMB-CNM, CSIC), Spain, from 2008 to 2012 , contracted by CIBER-BBN. Currently she is predoctoral FPI-2012 fellow at the Biomedical Application's Group at IMB-CNM. Specialized in electronic systems, her current researches interested are focused on design and development of electronic systems for biomedical applications, and also on electrochemical sensors for microfluidic cell culture devices.

Xavi Illa is a researcher of the CIBER-BBN enroled in the Biomedical Application's Group of the Microelectronics Institute of Barcelona, IMB-CNM (CSIC). He obtained the physics degree from the University of Barcelona in 2004, and the Ph.D. from the same institution in 2010 with a work focused on the development of a HPLC onchip device on new polymeric substrates. Now, his research interests are the design and fabrication of lab-on-a-chip devices for biomedical applications, based on both silicon and polymeric microtechnologies.

Ignacio Giménez obtained a Medical Doctor degree from University of Zaragoza (Spain) in 1992 and a PhD in Physiology in 1997. He gained postdoctoral experience at Yale University School of Medicine Department of Cell and Molecular Physiology (1998-2003) prior to his return to Spain as a Ramón y Cajal researcher (2003-2008). Since 2008 he is associate professor of Physiolgy at University of Zaragoza and Senior Researcher at Aragón's Health Sciences Institute. Dr. Gimenez's broad research interest is in establishing cell and molecular physiopathological mechanisms in renal and cardiovascular diseases. Currently his laboratory focuses in the development of biomimetic in vitro models of renal tubule function and disease.

Yoskaly Lazo obtained a degree in Pharmaceutical Sciences from University of La Habana (Cuba) in 2003 and a PhD degree in Physiology in 2009 from University of Zaragoza. After a two-year postdoctoral training at the National Health Institute
(Bethesda, USA) he moved to the Department of Medicine, Emory University School of Medicine where he is currently studying the function of ion transport in in vivo and ex vivo models of renal function and disease.

Rosa Villa is a permanent member of CSIC scientific staff since 1992. Obtained a medical degree from the University of Barcelona in 1981, and her Ph.D. from the Autonomous University of Barcelona in 1993. Currently she leads the Biomedical Application's Group of the Microelectronics Institute of Barcelona, which main research interests are the design and fabrication of Micro and Nano Systems for Biomedical Applications.

Abdelhamid Errachid graduated in physics from the University M. Ismail, Meknes, 1992 and received a PhD degree in electronic engineering from the Universitat Autonoma de Barcelona, Spain, in 1998. Since 2008, he had joined Laboratory of Analytical Sciences in Claude Bernard University-Lyon 1 as a full professor. He is now involved in several national and European projects. His current research activity is focused on bioelectronics, biofunctionalization and nanobiotechnology.

Gemma Gabriel obtained a chemistry degree from the Autonomous University of Barcelona in 2000, and her PhD in Materials Science in 2005. She joined a postdoc member of CSIC in the Biomedical Application's Group of the Microelectronics Institute of Barcelona. She is currently researcher (permanent staff of CSIC) in the Biomedical Applications Group. Her main research interests are development of technologies and to craft innovative multisensing devices (impedance, oxygen, $\mathrm{pH}$ ) capable of providing novel solutions to different applications in the biomonitoring field. Novel materials such as carbon nanotubes and graphene are implemented as biocompatible materials in biomedical applications. 